\title{
Do we need to decolonise bereavement studies?
}

\section{Sukhbinder Hamilton}

School of Education and Sociology, University of Portsmouth

\section{Berenice Golding}

School of Human and Social Sciences, University of Huddersfield

\section{Jane Ribbens McCarthy}

Open University; University of Reading

Jane.McCarthy@open.ac.uk

\section{Keywords: bereavement, aftermath of death, decolonisation, diversity, colonialism, grief}

\section{Beginning a conversation}

Despite spending almost the entirety of our lives in England, each of us has heritage from various parts of the world: Sukh (Punjabi, Indian), Berenice (dual heritage: white British and Jamaican), and Jane (white English, with a little touch of Irish). While our own biographies are now UK based, our discussion is global in scope, which necessarily informs our understandings. In different ways we are ourselves on a steep learning curve here, in attempting to address these topics. We start with extracts from a conversation we had before embarking on writing together:

\section{Abstract}

At this re-launch of the journal Bereavement, we explore the question, 'Do we need to decolonise bereavement studies?' We do not offer definitive answers, but rather seek to open up conversations. We briefly explore some of the main debates and explanations of what 'decolonising' means. In its broader understandings, this entails questions about the nature of the knowledge that underpins claims to 'expertise', since knowledge inevitably reflects the socio-historic position and biography of those who produce it. This raises uncomfortable issues about the 'universality' of that knowledge, and how to understand what is shared between human beings, including how to understand experiences of pain and suffering. In addressing the nature of 'bereavement studies', we first consider complexities of language and translation, before observing the heavy domination of the 'psy' disciplines in the affluent 'Minority World' (Punch, 2016), oriented towards individualised, medicalised and interventionist perspectives. We indicate work that seeks to challenge these limitations, including the decolonising of psychiatry itself. We argue the need for such decolonising approaches to go beyond cross-cultural work originating in the affluent 'Minority World', beyond interdisciplinarity, and beyond crucial work on equality, diversity and inclusivity. Bereavement, as a field of study and a set of practices, needs to take account of the legacies of complex colonial histories of exploitation and harm that continue to shape the world in general, and in particular, the aftermath of death in the continuing lives of the living. We conclude with some implications for 'bereavement' practice, from a UK perspective. 
Sukh: As this is a viewpoint article, it should be about trying to open up conversations around bereavement which are more representative of society. There should be open spaces for dialogue; spaces to open up conversations and acknowledging that actually we do bereavement in different ways. Ways that are deeply rooted in cultural practices, traditions and values that we have from our ancestors. One of the key things for me is understanding what is behind the rituals and practices and how to convey these (and the value of them) to the younger generation who often dismiss them as mumbo jumbo because that is what the education system, which is rooted in the colonial past, leads them to believe.

Berenice: I think for me, which goes back to Sukh's point, is that the bigger question is about the colonial past, and who is doing the decolonial work. There is a need to challenge the structures, the systems that mean that we don't learn about the legacies of empire, colonialism, and imperialism in the ways that we should. It is important that we do because of the effect that they have on us and how we develop a deeper understanding of the world that we live in.

Jane: Yes, and I'm aware in the field of decolonisation in academic work in general, there also seem to be strong moves towards starting from somewhere else, ie decentring 'the West'.

Berenice: I agree Jane. I have distinctly different experiences of funeral practices, rites, and rituals because of my dual heritage. We do things differently. When I think about the practices associated with my Jamaican heritage, they are built on a historic framework that can be traced back to slavery and the legacy of colonialism. There are traditional practices around bereavement, grieving, burial rites and practices, and the way we honour those, the ancestors, who have departed before us. It is important to me that we learn these practices and pass them on to the next generation so that they continue. For example, ensuring that the importance of the wake and 'nine night' are understood.

Jane: As a white English woman, I haven't much noticed the dominant assumptions surrounding bereavement in the UK, and it's been the work on family deaths in Senegal that has opened my eyes, and it's been so rewarding. Clearly, in the UK, if you have a heritage that isn't part of the dominant white British experience then that does provide another perspective, but does that itself get changed by living and working in Britain and within British institutions, as you are each suggesting? And that inevitable accommodation with mainstream ideas has always been true for feminist academic work too - dominant disciplines and knowledge have represented 'male' hegemony (which does oppress men as well as women); but how to really start from somewhere else? We end up always having to engage with the dominant knowledge forms. But I suppose the first step is to let go of the assumption that white 'western' knowledge is superior, and to begin to recognise and know what 'we' don't know.

Berenice: Absolutely. I suppose I'm thinking about the students that I work with and how their experiences of death, dying, grief and bereavement may be different. We experience bereavement differently but how much more might this differ based on our culture/heritage? I think that, at just, at a very basic level, you know, when we're making decisions about deadline extensions, for example, perhaps, if we are not sort of cognisant, you know, not aware of how different traditions/practices may affect that particular student, it might create further problems for them. I know that we treat students as individuals but I think that that's where some of this speaks to as well.

Sukh: The way we acknowledge, and if need be challenge these assumptions is absolutely key to moving forward. Recognising that decolonising is a tall order and being cognisant about this and, as we have discovered, agreeing on terminology that explains but is not itself detrimental is not straightforward or for the faint hearted.

Jane: Yes, questions of concepts, language and words are so important in all of this...

Beginning to write: The re-launch of the journal in its new format presents a great moment to reflect on the field of 'bereavement studies'. This is particularly appropriate in a journal that focuses specifically on 'bereavement', when so often this field is subsumed within the study of 'death, dying and bereavement' rather than clearly focusing on the continuing lives of the living over time after a significant death. This preliminary discussion seeks to open up constructive conversations from a decolonisation perspective, a process that has the potential to the benefit of all communities, and across the globe - which is arguably a very tall 
order. For many readers the term 'decolonisation' may be unknown or regarded with some anxiety as the most recent bandwagon trendy campaign. As academics and teachers, while the term has become reasonably familiar, we are ourselves endeavouring to learn and explore what a decolonial perspective brings, or indeed adds, to work on equality, diversity and inclusion. We consider, what is the basis of this knowledge that forms the primary foundation for 'bereavement studies', a knowledge base which also underpins professional and voluntary bereavement services. We ask, what is the nature of the 'expertise' that practitioners offer 'the bereaved', and what might decolonisation entail for 'the bereavement sector' as well as 'bereavement studies'?

\section{Decolonisation - what does it actually mean?}

As might be expected, this terrain is strongly oriented to global colonial histories. These histories have entailed the forceful removal of people from their land, the plundering of resources, slavery, genocide, the subjugation of peoples, as well as the denigration and destruction of 'their' own heritage (Lentin, 2020; Weisberger, 2021). The history of global colonialism is of course extremely complex and colonial powers have waxed and waned over millennia. If we consider western European imperial nations from the late 16th century, starting from trading relations, Britain in particular came to rule over the largest empire in history, claiming to be bringing enlightenment and civilisation to all corners of the globe. Notably, ideas of separate 'races' coincided with colonialism, as the framing of 'othering' (Hamilton \& Riordan, 2016), alongside imperial claims to be bringing enlightenment (Wade, 2014), and the rise and domination of eurocentrism (Said, 1978).

The legacy of colonialism is multifold. While former imperial powers have prospered (and continue to prosper) greatly from accumulated wealth, much of the 'Majority World' ${ }^{1}$ is still struggling with the fallout of colonial exploitation. This destructive legacy lives on in forms of global neo-colonial economic systems and institutions, exploitation and harm - including the terrible impact of the unfolding and catastrophic climate and ecological crisis - as well as historic, intergenerational trauma which lives on in families and communities.
Decolonial work thus raises wide-ranging global issues, including racialised histories of inequalities of resources and wealth. It is also concerned with very specific localised struggles, for example by indigenous communities over land rights. But there is a further question: what impact have these colonial histories had in terms of the dominant forms of knowledge which originated in the affluent 'Minority World'? Many of the key relevant disciplines were rooted and developed in colonial countries at the height of colonisation. Developmental psychology, for example, was largely established in the context of compulsory schooling in imperial Britain and elsewhere.

Attachment theory was developed in the aftermath of the displacements of war, but is being increasingly questioned as to its relevance beyond the affluent Anglophone locations in which it originated, and the ethics of applying it without recognition of this diversity (Keller, 2014; 2018; Rose \& Rose, 2016; Granqvist et al, 2017).

Decolonisation of this knowledge base requires a recognition that all knowledge is shaped by the social, political and cultural contexts in which it is produced - a viewpoint familiar to some in terms of feminist as well as Black standpoint theory (Mohanty, 2003; Harding, 2004). As Meghji observes, 'knowledge produced by dominant social groups tends to reproduce their worldview(s) while knowledge produced in the academy by marginalized people produces alternative "outsider" perspectives' (2020, p29). Thus, what uncomfortable questions does this raise about claims to the universality of that knowledge? ${ }^{2}$ What are the assumptions and omissions associated with that knowledge base? How are we to understand 'scientific facts', for example in the fields of health or psychology? Can we move beyond the binaries of truth and falsehood, functional and dysfunctional? What happens if we start from somewhere else? And who is this 'we' who are in a position to ask and answer such questions? Who is included, and who is excluded?

So, a decolonising perspective draws focused attention to the legacies of the past, through systems and structures that perpetuate inequalities and oppressions, or in terms of shared histories of trauma and how communities have collectively responded. Equally, it is about how this historic colonial legacy has shaped knowledge production and its underpinning assumptions that continue into the present. Further, how have these multiple, complex colonial histories shaped understandings 
of, and responses to, death and its aftermath? The picture that emerges is one of great historical and geo-political complexity, not least in terms of the diverse locations in which indigenous and previously colonised and enslaved peoples now reside around the world. And of course, some of this results from international migration that may itself be driven by these colonial histories and the vast global inequalities of the contemporary world.

\section{What is this field, 'bereavement studies'?}

One of the first awkward issues raised by this question is the recognition that the terms 'bereavement' and 'grief' themselves do not translate straightforwardly between different languages. Importantly, these are not minor matters, since language is integral to socio-cultural norms and possibilities which literally make experiences speak-able (Evans et al, 2017; Klass, 2017). Even within Anglophone worlds, do these terms convey or even indicate all that may be happening in the aftermath of a death, over time and space, in the continuing lives of the living?

As with many areas of study, 'bereavement studies' has the potential to be highly interdisciplinary, but the history of this field highlights how psychiatry and psychology have been, and continue to be, heavily dominant. And across the decades (O'Connor, 2019), empirical and theoretical models have continued to be overwhelmingly based in the affluent 'Minority World', with a medicalisation and individualisation of bereavement and grief largely oriented towards interventions designed to promote 'healthy' or 'functional' outcomes (Granek, 2017). Such work is heavily shaped by the cultural assumptions of the 'Minority World', in terms of individualised internal emotional processes of 'grief' (Rosenblatt \& Bowman, 2013; Klass, 2017). Indeed, the focus on the 'individual' itself marks affluent Anglophone cultures as quite atypical from a global perspective (eg Chan \& Chow, 2017; Davies, 2020; Eyetsemitan, 2021).

This in turn points to key anthropological and sociological questions about the cultural embeddedness of 'emotions' and whether, and how, they are spoken (Scheper-Hughes \&Lock, 1987; Palmer \& Occhi, 1999; Jakoby, 2012). It also highlights the potential range of questions, theoretical perspectives, and conceptual analyses that may be possible with a more interdisciplinary approach (Walter, 1999; Thompson et al, 2016; Ribbens McCarthy et al, in progress). Even within the affluent 'Minority World', more challenging perspectives on bereavement and grief, that raise political and sociological issues such as social justice and inequality, have only very recently been raised in relation to bereavement studies (Bordere \& Harris, 2016).

Our concern here is not to suggest that existing bereavement studies are not useful and important we are seeking to avoid such binaries - but to begin to consider their limitations and acknowledge their structural underpinnings and cultural assumptions, particularly in regard to what are sometimes referred to as the 'psy' disciplines. Such work has already started with some psychiatrists reflecting on the nature of their profession, including its financial as well as its cultural underpinnings (Kleinman, 2012). Bracken and colleagues (2021), for example, suggest the decolonisation of psychiatry requires: critical thinking and education - without defensiveness - about the history of psychiatry; the involvement of grassroots organisations and those with lived experience; and openness to understanding indigenous approaches to distress. Indeed, with regard to the latter point, both anthropologists and anthropological psychiatrists (eg Schweder et al, 1997; Kleinman, 2006) have offered extensive consideration of variable experiences of suffering and distress across the globe, which links also to the decolonisation of trauma studies (eg Goozee, 2012, Craps et al, 2015).

There are some sensitive issues here about how far decolonising and cross-cultural approaches overlap. Work on the cultural significance of 'grief' has been increasing over time, with Rosenblatt observing that 'No knowledge about grief is culture free' (2008, p207). Cross-cultural work may highlight this, creating challenges to dominant ways of thinking about 'bereavement' (Walter, 2010; Ribbens McCarthy et al, 2019). But cross-cultural work does not necessarily analyse the key historic origins of the structures of power and resources relevant to variable understandings and experiences of life after death. Nevertheless, implicitly, cultural narratives themselves have political significance, since they are bound up with collective discourses and power structures: 'A cultural narrative that guides individuals and families through their grief is the same cultural narrative that justifies some people having political power and not others' (Klass, 2017, p440). 
So a decolonisation approach potentially requires us to go much further, beyond cross-cultural work originating in the affluent 'Minority World', beyond interdisciplinarity, and beyond the concerns of equality, diversity and inclusion (crucial though these all are). Decolonising bereavement studies requires letting go of the certainties of current ways of thinking and current evidence based on models that have been theorised in the 'Minority World'. It requires consideration of how the colonial legacies of knowledge production may require us to start from somewhere else, perhaps from multiple starting points. This can be an unnerving, challenging and difficult prospect, but has the potential to bring new wisdom.

The challenge requires us to be open to the variability of human experience, and the implications for thinking, being and relating, in the presence of death and its aftermath in the lives of the living. But, besides being personally challenging, such work also faces the deeply embedded institutionalised structures that uphold the current field of bereavement studies. Such structures include, for example: formal international networks; the powerful medical organisations and professional associations that underpin psychiatry and psychology; and the access to resources that link with those.

Recognising the limitations of such institutionalised 'expertise' may be the first step. In this regard, it is notable that the UK Childhood Bereavement Network refers, not to bereavement expertise, but to 'communities of practice', potentially raising the question of which communities' practices are being drawn upon.

\section{Developing the conversations}

Decolonisation opens up major complex questions. Some of these are very painful and raise key issues of social justice, but they also have the potential to bring benefits. What does 'grief' look like, and is it really appropriate to frame 'bereavement' in terms of internal emotions such as 'grief'? Perhaps emotions and the materiality of life are inextricably bound up together (Ribbens McCarthy et al, 2020). What do people regard as a hopeful outcome of death and bereavement - perhaps death offers a welcome release from a terrible life of exploitation and hardship (Fletcher, 2021)? And perhaps a semblance of peace to those left behind? What really lies behind the diversity of rituals, funerals and bereavement customs? How are they experienced, and how are they embedded in very different understandings and beliefs? Such variability may include beliefs concerning what life is about, what it means to be a human being living in the world in particular circumstances, and how people relate to each other. What is the significance of ancestors and the continuing intergenerational ties and responsibilities between the living and the dead? It is clear that human beings manage life and death in multiple ways, but often prevalent expectations and assumptions themselves can have a power that potentially turns into disenfranchisement and 'policing' of 'grief', along with self-monitoring about what constitutes 'appropriate' responses to death.

Seeking to know and appreciate the multiple ways of responding to death and its aftermath in a deeply unequal world, shaped by colonial histories and forms of neo-coloniality, is a deeply challenging prospect. There are existing bodies of work that can help, including anthropological and cross-cultural endeavours, but there are also long histories of mistrust, histories that are ongoing in a world structured in ways that continue to fundamentally exploit and harm people with less power. For individuals to get past such mistrust, and speak up, is sometimes a very big ask, too big perhaps. But there is so much to be learned from each other in opening up conversations. Some insights may have direct policy implications in countries affluent enough to have formal bereavement provisions. And in a world facing catastrophe through climate and ecological crises, new forms of political or climate grief are emerging, and humanity needs all the resources that we can muster - personal, socio-cultural, material, emotional - in the face of such existential threats.

There will be valuable riches and wisdom in those conversations. And these will also be of benefit to all peoples in the affluent 'Minority World' who are minoritised, whether through racialised colonial histories, skin colour, faith group, sexual orientation, dis/ability, gender or deprivation and social class. As Kinouani asserts '...it's important to remember that colonialism did not only give us whiteness and white supremacy; colonial and imperial logics also gave us the foundation of eugenics, of disability, of homophobia... all those things come together. They can't be separated' (Kinouani \& Ellis, 2021). 
Asking these questions raises the most fundamental issues of what is shared and what differs between us as human beings and our experiences of life and death, and how that is shaped by historic and continuing inequalities of power and resources and contemporary diversity. Can we trust each other sufficiently to engage with such conversations?

\section{Implications for practice}

In this Viewpoint discussion we have argued that a decolonisation approach potentially requires us to go beyond cross-cultural work originating in the affluent 'Minority World', beyond interdisciplinarity, and beyond the concerns of equality, diversity and inclusion (EDI) (crucial though these are). In considering the implications for practice we are very conscious that these thoughts we offer here are particularly rooted in the UK and our experiences of 'bereavement' in this context, where EDI work is a widespread concern of many organisations. For readers in other locations, these may or may not be helpful suggestions, and might indeed be quite inappropriate and irrelevant.

Decolonial approaches to practice will be challenging but potentially rewarding, and will require flexibility in response, to recognise the complexity of people's situations and the long histories that have shaped their experiences of life. Such approaches require a focus on listening, respectfully and with humility, a readiness to learn and to be an ally, a friend walking alongside, rather than an expert. A decolonial awareness requires attention to how histories of marginalisation and inequality may be deeply ingrained over many centuries as well as within an individual's lifetime, creating significant harm, injustice, and barriers to trust. At the same time, the histories of individuals, their families and their communities, may be distinctive, leading to variable adherence to, and understandings about, traditional rituals, customs and practices, and the beliefs and philosophies on which they're based.

Acknowledgements: We would like to acknowledge the very helpful feedback we have received from some of the editorial board members of Bereavement.

\section{Notes}

1 "The terms "Majority World" and "Minority World" (see also Panelli et al, 2007) are used to refer to what has previously been known as the "third world" and the "first world" or more recently as the "Global South" and the "Global North". This acknowledges that the "majority" of population, poverty, land mass and lifestyles is located in Africa, Asia and Latin America (ie the
"Majority World"), while also encouraging us to question unequal global power relations where "western" and "northern" populations and issues tend to be privileged despite being the minority.' (Punch, 2016: 353).

2 Such questions, including the philosophical debates on standpoint theory, raise major questions of ontology and epistemology that may be familiar to social scientists but less familiar to others. The quote from Meghji makes a clear centrally relevant point.

\section{References}

Bracken P, Fernando S, Alsaraf M, Creed M, Double D, Gilberthorpe T et al (2021) Decolonising the medical curriculum: psychiatry faces particular challenges. Anthropology and Medicine.

https://doi.org/10.1080/13648470.2021.1949892

Chan SSY \& Chow AYM (2017) A cultural sociological review of Chinese funeral rituals'. In: GR Cox \& N Thompson (eds) Handbook of the sociology of death, grief, and bereavement, a guide to theory and practice [online]. Routledge. Available at: www.routledgehandbooks.com/doi/ 10.4324/9781315453859.ch24 (accessed 4 January 2022).

Craps S, Cheyette B, Gibbs S, Andermahr S \& Allwork L (2015) Decolonizing trauma studies round-table discussion. Humanities 4(4), 905-923.

https://doi.org/10.3390/h4040905

Davies DJ (2020) Dividual identity in grief theories, palliative and bereavement care. Palliative Care E Social Practice, 14, 1-12.

https://doi.org/10.1177/2632352420921867

Evans R, Ribbens McCarthy J, Fatou K, Bowlby S \& Wouango J (2017) Interpreting 'grief' in Senegal: language, emotions and cross-cultural translation in a francophone African context. Mortality, 22(2) 118-135.

https://doi.org/10.1080/13576275.2017.1291602

Eyetsemitan F (2021) Inequality, death and dying. Panel discussion. The 15th international conference on the social context of death dying and disposal, Manchester 1-4 September. Available at:

https://eu.eventscloud.com/website/4167/home/\#papers -section (accessed 5 December 2021).

Fletcher K (2021) A fight for burial rights: the importance of autonomous Black burial grounds then and now. The 15 th international conference on the social context of death dying and disposal, Manchester 1-4 September. Available at:

https://eu.eventscloud.com/website/4167/home/\#papers -section (accessed 5 December 2021).

Goozee H (2021) Decolonizing trauma with Frantz Fanon. International Political Sociology, 15(1). https://doi.org/10.1093/ips/olaa014

Granqvist P, Sroufe LA, Dozier M, Hesse E, Steele M, van Ijzendoorn M (2017) Disorganized attachment in infancy: 
a review of the phenomenon and its implications for clinicians and policy-makers. Attachment \& Human Development, 19(6) 534-558. https://doi.org/10.1080/14616734.2017.1354040

Granek L (2017) Is grief a disease? In: GR Cox \& N Thompson (eds) Handbook of the sociology of death, grief, and bereavement, a guide to theory and practice [online]. Routledge. Available at: www.routledgehandbooks.com/doi/ 10.4324/9781315453859.ch18 (accessed 4 January 2022).

Hamilton S \& Riordan T (2016) Diversity and race in a higher education context. In: W Sims-Schouten \& S Horton (eds) Rethinking social issues in education for the 21st century. Cambridge Scholars Publishing.

Harding S (ed) (2004) The feminist standpoint theory reader. Routledge.

Harris DL \& Bordere T (eds) (2016) Handbook of social justice in loss and grief: exploring diversity, equity and inclusion. Routledge.

Jakoby N (2012) Grief as a social emotion: theoretical perspectives. Death Studies 36(8) 768-711. https://doi.org/10.1080/07481187.2011.584013

Jullien F (2008/2014) (Trans Michael Richardson and Krzysztof Fijalkowski) On the universal, the uniform, the common and dialogue between cultures. Polity Press.

Keller H (2014) Introduction: understanding relationships - what we would need to know to conceptualise attachment as the cultural solution to a universal need. In: H Ottoman \& H Keller (eds) Different faces of attachment: cultural variation on a universal human need. Cambridge University Press.

Keller H (2018) Universality claim of attachment theory: children's socioemotional development across cultures. Proceedings of the National Academy of Sciences of the United States of America 115(45) 11414-11419.

Kinouani G \& Elllis E (2021) The big conversation: healing from racial trauma. Available at: www.bacp.co.uk/bacpjournals/therapy-today/2021/october-2021/the-big-conve rsation/ (accessed 7 August 2021).

Klass D (2017) The cross-cultural study of grief. In: GR Cox \& N Thompson (eds) The Routledge companion to death and dying [online]. Routledge. Available at: www.routledgehandbooks.com/doi/10.4324/97813157237 47.ch40 accessed 4 January 2022).

Kleinman A (2006) What really matters: Living a moral life amidst uncertainty and danger. Oxford University Press.

Kleinman A (2012) The art of medicine: culture, bereavement, and psychiatry. The Lancet, 379(9816), 608-9. https://doi.org/10.1016/S0140-6736(12)60258-X

Lentin A (2020) Why race still matters. Polity Press.

Meghji A (2021) Decolonizing sociology. Polity Press.

Mohanty CT (2003) 'Under Western eyes' revisited: feminist solidarity through anticapitalist struggles. Signs, 28(2) 499-535.

O'Connor MF (2019) Grief: A brief history of research on how body, mind, and brain adapt. Psychosomatic Medicine, 81(8) 731-738.

https://doi.org/10.1097/PSY.0000000000000717
Palmer GB \& Occhi DJ(1999) Introduction: linguistic anthropology and emotional experience. In: GB Palmer \& DJ Occhi (eds) Languages of sentiment: Cultural constructions of emotional substrates. John Benjamins, pp 1-24.

Punch S (2016) Cross-world and cross-disciplinary dialogue: A more integrated, global approach to childhood studies. Global Studies of Childhood, 6(3) 352-364.

Ribbens McCarthy J, Evans R \& Bowlby S (2019) Diversity challenges from urban West Africa: how Senegalese family deaths illuminate dominant understandings of bereavement. Bereavement Care, 38(2-3) 83-90. https://doi.org/10.1080/02682621.2019.1679468

Ribbens McCarthy J, Evans R, Bowlby S \& Wouango J (2020) Making sense of family deaths in urban Senegal: diversities, contexts and comparisons. OMEGA - Fournal of Death and Dying, 82(2) 230-260. https://doi.org/10.1177/0030222818805351

Ribbens McCarthy J, Woodthorpe K \& Almack K (in progress). The aftermath of death in the continuing lives of the living: re-framing 'bereavement' through family sociology.

Rosenblatt PG (2008) Grief across cultures: a review and research agenda. In: MS Stroebe, RO Hansson, H Schut \& W Stroebe (eds) Handbook of bereavement research and practice: Advances in theory and intervention. American Psychological Association, 207-222.

Rosenblatt, P and Bowman, T (2013). 'Alternative approaches to conceptualizing grief: a conversation'. Bereavement Care, 32(2): 82-85.

Said E (1978) Orientalism. Routledge \& Kegan Paul Ltd.

Scheper-Hughes N \& Lock M (1987) The mindful body: a prolegomenon to future work in medical anthropology. Medical Anthropology Quarterly, New Series 1(1) 6-41.

Schweder RA, Much NC Mahapatra M \& Park I (1997) The 'big three' of morality (autonomy, community and divinity) and the 'big three' explanations of suffering. In: AM Brandt \& P Rozin (eds) Morality and health. London: Routledge.

Thompson N, Allan J, Carverhill P, Cox GR, Davies B, Doka K et al (2016) The case for a sociology of death, dying and bereavement, Death Studies, 40 (3) 172-181. https://doi.org/10.1080/07481 187.2015.1109377

Wade P (2014) Race, ethnicity, and technologies of belonging. Science, Technology, \& Human Values, 39(4) 587596. https://doi.org/10.1177/0162243913516807

Walter T (1999) On bereavement: The culture of grief. Open University Press.

Walter T (2010) Grief and culture. Bereavement Care, 29(2) 5-9. https://doi.org/10.1080/02682621003707431

Weisberger M (2021) Remains of more than 1,000 indigenous children found at former residential schools in Canada. Live Science. Available at: www.livescience.com/childrens-graves-residential-schoolscanada.html (accessed 24 November 2021). 